\title{
A literature review on COVID-19 [coronavirus] research specific to Australia including manuscripts on policy and media releases
}

\section{Deborah Joy Hilton}

Deborah Hilton Statistics Online. deborah.hilton@gmail.com

\begin{abstract}
INTRODUCTION / OBJECTIVES: Comprehending the avalanche of statistical research on COVID-19 [coronavirus] is laborious. Predictions, forecasts, and diagnostic algorithms are important for planning, allocation, and meeting the needs of the increasing population disease burden. Statisticians must be aware of spreadsheets, databases, and calculation methodology to produce valid estimates. Policymakers, government officials, and planners interpret results and read reports without knowing calculation intricacies. Health care workers must be aware of scientific websites whilst they are under increasing stress due to aging populations and improved technology. It is important that context-specific information is sought, read, and understood. METHODS: A literature review was undertaken to find contextspecific statistical research information on COVID-19. The author performed a Pubmed search, a search utilising the coronavirus MeSH terms (Medical Subject Headings), adding the additional MeSH terms of Australia AND policy, and then another search with media as a text word. RESULTS: The Pubmed search, utilising the MeSH (Medical Subject Headings) on coronavirus, adding the MeSH terms [Australia AND Policy] resulted in 52 records being retrieved. The Australian Government Department of Health website dedicated link listing coronavirus (COVID-19) news reports, statements, and media releases included 347 departmental media retrievals. CONCLUSION: The COVID-19 pandemic has posed itself as the most critical health issue of the 21st century. It is important to understand the quality evidence-based information within the context, specific to the reason for seeking information so that wellinformed decisions are made that relate to preventative actions, early detection, and treatment options.
\end{abstract}

MESH I KEYWORDS: Information literacy. Information dissemination. SARS-CoV-2. COVID-19. 


\section{Introduction / Objectives}

Not limited to the topic of coronavirus, but worldwide due to the technological revolution, globally, there is an avalanche of information on topics generally. Glasziou reports on this issue recognizing an inescapable and growing information problem. ${ }^{1}$

Various authors have attempted to consolidate the scientific information on the coronavirus pandemic, with one publication by Oliveira and colleagues who performed a bibliometric analysis of the scientific

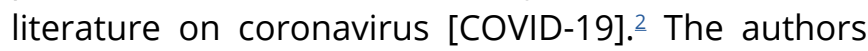
utilised, the ISI Web of Knowledge/Web of Science (WOS) as the database and gathered data in May 2020. The data analysis was performed using the HistCiteTM software, version 9.8.24, and the VOSviewer bibliometric analysis software, version 1.6.8. These researchers found 2,625 published papers in 859 different journals that are indexed in WOS that incorporated 9,791 authors across 3,365 research institutions, spanning 105 countries.

PubMed ${ }^{\circledR}$ is accessible to both the public and scientific community. $\frac{3}{-}$ Available to the public online since 1996, PubMed ${ }^{\circledR}$ was developed and is maintained by the National Centre for Biotechnology Information (NCBI), at the U.S. National Library of Medicine (NLM), located at the National Institutes of Health (NIH). According to the website, when accessed in 2021, PubMed $\AA$ information comprises more than 33 million citations for biomedical literature from MEDLINE, life science journals, and online books. In various instances, citations may allow access to full-text content from PubMed Central and other publisher and journal websites.

In addition, informed healthcare decision-making can also be achieved by utilising the Cochrane Library (ISSN 1465-1858), which is a collection of databases with independent evidence resources that are of high quality and hence enable informed decision making. ${ }^{4}$ The Cochrane Library is owned by Cochrane and published by Wiley. The systematic reviews in health care are detailed in the Cochrane Database of Systematic Reviews (CDSR). The randomized and quasi-randomized controlled trials are listed in the Cochrane Central Register of Controlled Trials (CENTRAL). There are also links to the Cochrane Clinical Answers and Special Collections featured on the website.
Searches of PubMed and the Cochrane Library were performed. The objective was to search in order to obtain scientific literature relevant and specific to Australia and to assess, then, the social impact and policy implications relevant to the Australian context. Furthermore, a properly documented overview of the Australian media coverage of COVID, with specific timeframes, keyword searches, and type of media coverage, was done. The overview discusses how the media reports referenced the scientific output and highlight various scientific resources utilised.

\section{Methods}

The author performed various searches, including a PubMed search using the search term; 'coronavirus.' This was refined by selecting article type either; clinical trial, meta-analysis, randomized controlled trial, or systematic review and selecting publication date; in the last year.

Alternatively, a search strategy was created using the MeSH Browser. The MeSH (Medical Subject Headings) is the NLM controlled vocabulary thesaurus used for indexing articles for PubMed and can be found at; https://www.ncbi.nlm.nih.gov/mesh.

A literature review was undertaken to find contextspecific statistical research information on COVID-19. The author performed a Pubmed search, a search utilising the coronavirus MeSH terms (Medical Subject Headings), adding the additional MeSH terms of Australia AND policy, and then another search with the MeSH term of Australia but not Policy, but the text word media. The first MeSH search hence was; (((("SARS-CoV-2"[Mesh]) OR "COVID-19"[Mesh]) OR "Coronavirus"[Mesh]) AND "Australia"[Mesh]) AND "Policy"[Mesh].

Filters of meta-analysis, systematic review, randomized controlled trial, or clinical trial in the last year were utilised to narrow the search results. Afterward, the same initial search string was utilised without the MeSH term "Policy" but adding the text word; 'media' again without the filters.

A search of the Cochrane Library was performed using the search term; 'coronavirus' to obtain Cochrane systematic reviews and trials. ${ }^{4}$ 
The Australian Government Department of Health website lists all the coronavirus (COVID-19) news and media, including news reports, statements, and media releases on a dedicated link. .5 A search of this website was also performed using firstly the text word; coronavirus, then text words; coronavirus policy.

\section{Results}

The Pubmed search using the search term; 'coronavirus' yielded 159,496 results. The filter refinement by selecting specific article types and publications in the last year, detailed in the methods, reduced the number of results to 3,215 . Utilising the MeSH Browser search strategy for coronavirus terms described above with the MeSH terms "Australia" AND "Policy" resulted in 52 records being retrieved. The filters of article type and publication in the last year reduced the number of results obtained to 14. Adding the text work AND 'media' to the initial coronavirus search string [with the MeSH term "Australia" but not with the MeSH term 'Policy" nor the filters] resulted in 64 retrievals.

The search of the Cochrane library that was performed prior to the abstract presentation in Dec 2020, which is described in the methods, yielded 19 Cochrane reviews [peer-reviewed systematic reviews] and 1591 trials that matched coronavirus in the title abstract keyword. Repeating this search in April 2021 increased the number of hits obtained to 27 Cochrane reviews and 2803 trials. Repeating this in Dec 2021 yielded 35 Cochrane reviews and 4911 trials.

The Australian Government Department of Health website, with the dedicated link listing all the coronavirus (COVID-19) news reports, statements, and media releases, retrieved 347 coronaviruses [Covid-19] news, statements, or media releases that were listed under departmental media when the search was completed in August. $\frac{5}{}$ The dates of these retrievals were from 19th January 2020 to 6th August 2021. Seventy-three retrievals were from the Australian Health Protection Principal Committee (AHPPC). The others included a range of topics such as covid safe App, mass gathering updates, public transport, mental health impacts, restrictions, specific localities, masks, quarantine, funding, private sector partnerships, job-keeper, Medicare, remote areas, pandemic response plans, schools, aged care sectors, research support, testing, local transmission, specific hot spots, specific lockdowns, TGA approval for vaccines, new variants, misinformation, thrombosis, clotting, workforce issues and the Australian Technical Advisory Group on Immunisation reports. More specifically, if a search of this website was performed for coronavirus policy, 235 health sector retrievals \& 131 departmental media reports were identified.

\section{Discussion}

If you consider the results of these Pubmed and Cochrane library searches that were located, this equates to a good quantity of quality information. The results were narrowed considerably utilising the [Mesh] search string, focusing on the Australian context, media reports, and policy response.

The Pubmed search that included the coronavirus Mesh search string with AND "Australia"[Mesh]) AND "Policy"[Mesh] added to the string retrieved a number of manuscripts focusing on policy within the Australian context. In addition, if the reference lists of these articles were viewed, other useful references could be located and retrieved.

Australian health authorities implemented a number of non-pharmaceutical intervention measures to mitigate the infection rate..

Specifically, the policy was considered in the manuscript titled; Recovery from the pandemic: evidence-based public policy to safeguard health. ${ }^{?}$ It discusses how Australia is comparing well by international standards, even though Victoria faced a second wave of infections.

The government has heeded the advice of scientists and evidence to ensure the public maintains strict physical distancing and mask-wearing as required [the latter in Victoria]. The authors state that the avoidance of high COVID-19 case numbers and death rates in Australia is due to evidence-based decision-making.

In addition, testing, case identification, and contact tracing policies effectively improve health outcomes. ${ }^{-}$

Hilton reports on the compliance with mask-wearing in Victoria after a new ruling making mask-wearing in public compulsory. $\underline{9}$ 
One manuscript was titled; COVID-19: A tale of two pandemics across the Asia Pacific region. ${ }^{10}$ It discusses how COVID has had considerably less effect in geographically isolated countries being Australia and New Zealand when compared to the disastrous impact in countries such as China, Italy, Great Britain, America, and Brazil.

Also, the effects of border shutdowns on the spread of COVID-19 were effective for Australia. ${ }^{11}$ Only four days after implementing the border restriction policy, the number of COVID-19 cases dropped by $94.4 \%$ in Australia. Hu and colleagues in their paper also report results indicating that travel restrictions and social distancing measures are effective in containing the transmission of COVID-19. ${ }^{12}$

Blakely and co-authors report on the ten-point plan to maximise the chance of successful elimination of community transmission of SARS-CoV-2 in Victoria, based on the lockdown from 9 July 2020 for 6 -weeks (as published on 17 July 2020). $\frac{13}{}$ The modelling included four simulated policy approaches; standard, standard with masks at 50\%, stringent with masks at 50\%, and stringent with masks at $90 \%$. The report states that "modelling suggests that elimination could have been achieved if Victoria had gone into stage 4 lockdown immediately from 9 July".

There is debate, controversies, and different messages over the beneficial use of face masks for preventing COVID-19 spread, and hence further investigation on their use is warranted. 14

Various authors report limiting human mobility during pandemics. ${ }^{15,16}$ Hakim and the authors report that community mobility decreased in Australia. They also investigated seven types of mitigation policies (mass gathering restrictions, international travel restrictions, passenger screening, traveller isolation/ quarantine, school closures, business closures, and domestic movement restrictions). They state that public policies have differing impacts on mobility and transmission. Wang and colleagues performed a state-level empirical study that assessed mobility and the association with the COVID-19 spread in eight Australian states/territories. Implementation in the early stages of the pandemic of social restriction policies limiting human mobility effectively controlled the COVID-19 spread. 16
Another manuscript evaluated various mitigation policies that aimed at slowing the spread and protecting individuals. $\frac{17}{}$ Temporal and spatial aspects influence the number of daily new cases from the states and territories.

Only a few days after implementing business and border restrictions, there was a decrease in the number of new cases. Gathering restrictions, however, may not be effective.

Scott and colleagues published a manuscript titled; Modelling the impact of relaxing COVID-19 control measures during a period of low viral transmission. 18 They found support for work from home policies (for minimising public transport use) and approaches for minimizing the risk associated with social venue reopening.

Byambasuren and colleagues published another manuscript worthy of attention, and it is titled; Estimating the extent of asymptomatic COVID-19 \& its potential for community transmission: systematic review and meta-analysis. ${ }^{19}$ The authors concluded that policy attention is still warranted even though the 1-in-6 prevalence estimate of asymptomatic COVID-19 cases \& asymptomatic transmission rates are lower than those of many highly publicized studies.

Within other settings such as schools, there is a heterogeneous and complex evidence base of implemented measures. $\underline{20}$ The authors wanted to gauge what evidence exists to design future reviews.

The Australian printed media were slow to report the COVID-19 pandemic. ${ }^{21}$ In addition, they were reluctant to allocate blame until the end of the study time, after confirmed case rates had begun to slow.

A pandemic can proliferate fear, anxiety, and even paranoia among people. ${ }^{22}$ The government should address risks resulting from conspiracy theories and false representations by focusing on scientificallybased public health messaging. They also need to be assertive against people who make false representations to protect consumers who may be vulnerable.

Pickles and colleagues state that COVID-19 misinformation is common globally, being 
disseminated via social media platforms and various other information systems. $\underline{23}$ Public health communications must ensure that beliefs based upon misinformation are identified so that efforts are not undermined.

The news and media reports on the Australian Government Department of Health website [coronavirus (COVID-19) news and media] include information on how COVID-19 vaccines work, doses, approval, recommendation \& information relating to; Vaxzevria (AstraZeneca), Comirnaty (Pfizer), Spikevax (Moderna). .5 There is advice for vaccination providers in the Statement on the relative timing of administering influenza vaccines and COVID-19 vaccines in 2021.

There is also information on the immunization policy, regulation \& governance in Australia, including the National Immunisation Program (NIP), Aust. Technical Advisory Group on Immunisation (ATAGI), The Therapeutic Goods Administration (TGA), Office of the Gene Technology Regulator (OGTR) \& Immunisation Coverage.

These documents utilize various scientific publications, some of which are detailed below.

A news statement to the general public in April 2020 reports on nowcasting, which is the concept of using previous 14-day data to help accurately understand the current epidemic state, considering the known time from infection to illness. ${ }^{24}$ Nowcasting is done by a team from the University of Melbourne [Doherty Institute]. $\frac{25}{}$

An updated statement from the Australian Health Protection Principal Committee (AHPPC) on the role of asymptomatic testing for COVID-19 refers to the Australian National Disease Surveillance Plan for COVID-19. $\underline{\underline{26}}$ This document details surveillance approaches, strategies, goals, indicators, national plans, epidemic activity monitoring, serosurveillance testing, and distancing. They state that expert guidance does not support large-scale, non-targeted, asymptomatic testing in Australia. The reasons are that it is neither epidemiologically proven nor a cost-effective method for case identification to prevent disease transmission.

On the Government website, other documents relate to the National approach to disease surveillance for
COVID-19 being the ongoing systematic collection, analysis, \& interpretation of health-related information. This epidemiological information informs the Aust. Government's public health policy to stop the spread of COVID-19 in Australia.

A statement from the Australian Health Protection Principal Committee (AHPPC) on the review of physical distancing and person density restrictions refers to a study that examined the distribution of influenza virus, showing a greater risk of transmission if within $1.8 \mathrm{~m}$ of an infected individual. ${ }^{27}$ This research, combined with emerging evidence from where COVID-19 was first detected in China, shows that a major route of COVID-19 transmission is via droplets. As a result, the Australian Government advised people to maintain a distance of $1.5 \mathrm{~m}$ from others.

A news report on 3 August 2021 links to the Doherty Modelling Report for National Cabinet - 30 July 2021.28 This report was revised on 10 August 2021. This report includes COVID-19 infection and vaccination models utilised to define vaccine coverage target levels for transition to the National plan - phase B.

On 17 June 2021, a statement from Professor Paul Kelly, Australian Government Chief Medical Officer, in response to the latest Australian Technical Advisory Group on Immunisation (ATAGI) advice on COVID-19 vaccines was directed towards the general public. $\underline{29}$ According to evidence from the UK, they state that the rate of thrombosis with thrombocytopenia syndrome (TTS) after the second dose of AstraZeneca is significantly lower than for the first doses. This builds on a previous document where this complication was mentioned, titled; Safety of Australians our No. 1 priority. $\frac{30}{}$

Specifically, on this topic, a joint news statement from the Australian Technical Advisory Group on Immunisation (ATAGI) and the Thrombosis and Haemostasis Society of Australia and New Zealand (THANZ) on Thrombosis with Thrombocytopenia Syndrome (TTS) and the use of COVID-19 Vaccine AstraZeneca was posted to the general public. ${ }^{31}$ According to UK data, they state that the risk of TTS is much lower with a second dose, with 15 cases reported to date out of 9.0 million second doses of COVID-19 Vaccine AstraZeneca. This translates into an estimated rate of 1.7 cases per million doses. 
There are also various other documents on the Government website that include those related to investment in COVID-19 clinical trials, information on funding of crucial research to investigate effective mechanisms for preventing COVID-19 \& treatment of COVID-19 symptoms. ${ }^{5}$ Such mechanisms can then be translated into policy or practice.

There is also information on recommencing quarantine, travel from New Zealand to Australia, returning Australian children, and the continued pause to New Zealand green zone flights as examples. Whether it be Pubmed retrievals, Cochrane reviews, and/or information located on the Department of Health website, cumulative there are many manuscripts or reports. Glasziou states that focus on terms of research and practice effort needs to be on the better organizing, filtering, and use of the research that we have. ${ }^{1}$ This is to ensure that there is not a widening of the gap between what we know and what we do.

Prior to the pandemic, estimates were that $>85 \%$ of research is wasted due to poor methodological design or poor research questions, inadequate study procedure, or results being inadequately or not reported. ${ }^{32}$ The response to the global pandemic is a maelstrom of global research with varying consequences. ${ }^{33}$ In Covid-19 research, many of the above-mentioned research problems are magnified due to insufficient infrastructure and time constraints.

The complexity of the policy process is outlined in the manuscript on the purple patch for evidence-based health policy. They state that while evidence to clinical care is relatively linear, it is more complex translating evidence to public policy. 34

A quote by Joseph Stalin is useful to remember when understanding information such as that related to a pandemic. If you consider how important it is to continue reading information when there is a vast amount to comprehend, you must consider your purpose in reading. Is it to help the masses, or is it a personal endeavor to assist a single person? This can be summed up well with this quote by Joseph Stalin. "A single death is a tragedy; a million deaths is a statistic." If your loved one has coronavirus, then you may be reading to prevent a catastrophic or tragic single incident, whereas if you are reading as a statistician, politician, and/or even a clinician, you are probably aiming more to help the crowds or many people with your efforts. Morbidity and mortality in the latter case are viewed through a different lens or set of glasses.

The Internet is transformative in our world, greatly facilitating our access to information and hence opportunities. $\frac{35}{n}$ Understanding the limits of information in technorealism states that an excess of information is a primary example of the law of diminishing returns in action. $\frac{36}{6}$ This means that we become apathetic to it as more information becomes available to us.

In order to prevent the overload of information, some of which may not be factual, evidence-based information must be available so that well-informed decisions can be made that relate to preventive actions, early detection, and choice of treatment options.

Data registries that also allow accurate, thorough monitoring of case numbers, morbidity, and mortality are also paramount. There is considerably more information on coronavirus on PubMed than what was retrieved with this search as it was specific being focused on Australia. Searches need to be precise and targeted to the topic of interest.

\section{Conclusion}

The COVID-19 pandemic has posed itself as the most critical health issue of the 21 st century. A tremendous amount of COVID information is available to the public. The saturation of the community with COVID-19 information is also from various diverse sources, scientific and unscientific. The world has faced not only a pandemic but associated with that globally a vast number of scientific publications, databases, and general covid websites on the topic making it laborious to comprehend for scientists and community members alike. PubMed $₫$ searches can be refined to be targeted to a topic as in this case whereby the search focused on the policy response in Australia.

The summaries that are prepared that are uploaded on sites such as the Australian Government Department of Health website, are succinct and evidence-based with many referring to scientific publications, hence these are the preferred media, statement, and news sources of information for the general public. 


\section{Competing interests}

No financial, legal, or political conflicts involving third parties (government, corporations, and private foundations, etc.) have been declared for any aspect of the submitted work (including, but not limited to grants and funding, advisory board participation, study design, preparation of the manuscript, statistical analysis, etc.).

\section{References}

1. Glasziou P. Managing the evidence flood. Surg Clin North Am. 2006;86(1):193-9. https://doi.org/10.1016/j.suc.2005.10.016

2. Oliveira EMN, Carvalho ARB, Silva JSE, Sousa Neto AR, Moura MEB, Freitas DRJ. Analysis of scientific production on the new coronavirus (COVID-19): a bibliometric analysis. São Paulo Med J. 2021;139(1):3-9. https://doi.org/10.1590/1516-3180.2020.0449. R1.01102020

3. PubMed [Internet]. Bethesda (MD): National Library of Medicine (US), National Center for Biotechnology Information. Available from: https://pubmed.ncbi.nlm.nih.gov/

4. The Cochrane Library [Internet]. London (Uk): Willey InterScience; 1999. Available from: https://www.cochranelibrary. $\mathrm{com} /$

5. Australian Government Department of Health (Australia). Coronavirus (COVID-19) pandemic [Internet]. Australia: Department of Health; 2020. Available from: https://www.health. gov.au/news/health-alerts/novel-coronavirus-2019-ncov-healthalert/coronavirus-covid-19-news-and-media

6. Cook MJ, Dri GG, Logan P, Tan JB, Flahault A. COVID-19 Down Under: Australia's initial pandemic experience. Int J Environ Res Public Health. 2020;17(23):8939. https://doi.org/10.3390/ ijerph17238939

7. Lo SN, Skarbek A, Capon A. Recovery from the pandemic: evidence-based public policy to safeguard health. Med J Aust. 2020;213(6):284-284.e1. https://doi.org/10.5694/mja2.50748

8. Kuster AC, Overgaard HJ. A novel comprehensive metric to assess effectiveness of COVID-19 testing: Inter-country comparison and association with geography, government, and policy response. PLoS One. 2021;16(3):e0248176. https://doi. org/10.1371/journal.pone.0248176

9. Hilton DJ. Compliance with mask wearing in Victoria, after new ruling making mask wearing in public compulsory [Internet]. 2021(8);7-15. Available from: http://www.journalsonline.org/ american-journal-of-humanities-and-social-science/volume-8.php

10. Fitzgerald DA, Wong GWK. COVID-19: A tale of two pandemics across the Asia Pacific region. Paediatr Respir Rev. 2020;35:75-80. https://doi.org/10.1016/j.prrv.2020.06.018
11. Kang N, Kim B. The Effects of Border Shutdowns on the Spread of COVID-19. J Prev Med Public Health. 2020;53(5):293-301. https://doi.org/10.3961/jpmph.20.332

12. Hu HY, Yan F, Zhu JM, Karuno AP, Zhou WW. Intercontinental transmission and local demographic expansion of SARSCoV-2. Epidemiol Infect. 2021;149:e94. https://doi.org/10.1017/ S0950268821000777

13. Blakely T, Thompson J, Carvalho N, Bablani L, Wilson N, Stevenson M. The probability of the 6-week lockdown in Victoria (commencing 9 July 2020) achieving elimination of community transmission of SARS-CoV-2. Med J Aust. 2020;213(8):349-51.e1. https://doi.org/10.5694/mja2.50786

14. Bakhit M, Krzyzaniak N, Scott AM, Clark J, Glasziou P, Del Mar C. Downsides of face masks and possible mitigation strategies: a systematic review and meta-analysis. BMJ Open. 2021;11(2):e044364. https://doi.org/10.1136/ bmjopen-2020-044364

15. Hakim AJ, Victory KR, Chevinsky JR, Hast MA, Weikum D, Kazazian L, et al. Mitigation policies, community mobility, and COVID-19 case counts in Australia, Japan, Hong Kong, and Singapore. Public Health. 2021;194:238-44. https://doi. org/10.1016/j.puhe.2021.02.001

16. Wang S, Liu Y, Hu T. Examining the Change of Human Mobility Adherent to Social Restriction Policies and Its Effect on COVID-19 Cases in Australia. Int J Environ Res Public Health. 2020;17(21):7930. https://doi.org/10.3390/ijerph17217930

17. Ip RHL, Demskoi D, Rahman A, Zheng L. Evaluation of COVID-19 Mitigation Policies in Australia Using Generalised SpaceTime Autoregressive Intervention Models. Int J Environ Res Public Health. 2021;18(14):7474. https://doi.org/10.3390/ijerph18147474

18. Scott N, Palmer A, Delport D, Abeysuriya R, Stuart RM, Kerr CC, et al. Modelling the impact of relaxing COVID-19 control measures during a period of low viral transmission. Med J Aust. 2021;214(2):79-83. https://doi.org/10.5694/mja2.50845

19. Byambasuren O, Cardona M, Bell K, Clark J, McLaws ML, Glasziou P. Estimating the Extent of Asymptomatic COVID-19 and Its Potential for Community Transmission: Systematic Review and Meta-Analysis. JAMMI. 2020;5(4):223-34. https://doi.org/10.3138/ jammi-2020-0030

20. Krishnaratne S, Pfadenhauer LM, Coenen M, Geffert K, JungSievers C, Klinger C, et al. Measures implemented in the school setting to contain the COVID-19 pandemic: a scoping review. Cochrane Database Syst Rev. 2020;12:CD013812. https://doi. org/10.1002/14651858.CD013812

21. Thomas T, Wilson A, Tonkin E, Miller ER, Ward PR. How the Media Places Responsibility for the COVID-19 Pandemic-An Australian Media Analysis. Front Public Health. 2020;8:483. https://doi.org/10.3389/fpubh.2020.00483 
22. Freckelton Qc I. COVID-19: Fear, quackery, false representations and the law. Int J Law Psychiatry. 2020;72:101611. https://doi.org/10.1016/j.ijlp.2020.101611

23. Pickles K, Cvejic E, Nickel B, Copp T, Bonner C, Leask J, et al. COVID-19 Misinformation Trends in Australia: Prospective Longitudinal National Survey. J Med Internet Res. 2021;23(1):e23805. https://doi.org/10.2196/23805

24. Australian Government Department of Health (Australia). Modelling the current impact of COVID-19 in Australia [Internet]. Australia: Department of Health; 2020. Available from: https:// www.health.gov.au/resources/publications/modelling-the-currentimpact-of-covid-19-in-australia

25. Australian Government Department of Health (Australia). Australian Health Protection Principal Committee (AHPPC) coronavirus (COVID-19) statement on 16 April 2020 [Internet]. Australia: Department of Health; 2020. Available from: https:// www.health.gov.au/news/australian-health-protection-principalcommittee-ahppc-coronavirus-covid-19-statement-on-16april-2020

26. Australian Government Department of Health (Australia). Australian National Disease Surveillance Plan for COVID-19 [Internet]. Australia: Department of Health; 2020. Available from: https://www.health.gov.au/resources/publications/australiannational-disease-surveillance-plan-for-covid-19

27. Australian Government Department of Health (Australia). A statement from the Australian Health Protection Principal Committee (AHPPC) on the review of physical distancing and person density restrictions [Internet]. Australia: Department of Health; 2020. Available from: https://www.health.gov.au/ news/australian-health-protection-principal-committee-ahppcstatement-on-the-review-of-physical-distancing-and-persondensity-restrictions

28. The Peter Doherty Institute for Infection and Immunity (Australia). Doherty Modelling Report for National Cabinet [Internet]. Australia: Doherty Institute; 2021. Available from: https://www.doherty.edu.au/uploads/content_doc/ DohertyModelling NationalPlan including adendmum.pdf
29. Australian Government Department of Health (Australia). Statement in response to the latest ATAGI advice [Internet]. Australia: Department of Health; 2021. Available from: https:// www.health.gov.au/news/statement-in-response-to-latest-atagiadvice

30. Australian Government Department of Health (Australia). Safety of Australians our No. 1 priority [Internet]. Australia: Department of Health; 2021. Available from: https://www.health. gov.au/news/safety-of-australians-our-no-1-priority

31. Australian Government Department of Health (Australia). Joint statement from ATAGI and THANZ on Thrombosis with Thrombocytopenia Syndrome (TTS) and the use of COVID-19 Vaccine AstraZeneca [Internet]. Australia: Department of Health; 2021. Available from: https://www.health.gov.au/news/ joint-statement-from-atagi-and-thanz-on-thrombosis-withthrombocytopenia-syndrome-tts-and-the-use-of-covid-19-vaccineastrazeneca

32. Chalmers I, Glasziou P. Avoidable waste in the production and reporting of research evidence. Lancet. 2009;374(9683):86-9. https://doi.org/10.1016/S0140-6736(09)60329-9

33. Glasziou PP, Sanders S, Hoffmann T. Waste in covid-19 research. BMJ [Internet]. 2020;369:m1847. Available from: https:// www.bmj.com/content/bmj/369/bmj.m1847.full.pdf

34. Cormack M, Boxall AM, Hullick C, Booth M, Gruen RL. A purple patch for evidence-based health policy? Aust Health Rev. 2021;45(1):74-6. https://doi.org/10.1071/AH21016

35. Rosen L. Abstract [Internet]. Technorealism. Available from: https://cs.stanford.edu/people/eroberts/cs181/projects/ technorealism/abstract.html

36. Postman N. The Information Glut [Internet]. Technorealism. Available from: https://cs.stanford.edu/people/eroberts/cs201/ projects/technorealism/glut.htm 